\title{
18 METHOD DIFFUSION AS A SOCIAL MOVEMENT
}

\author{
Paul Beynon-Davies \\ Michael D. Williams \\ European Business Management School \\ University of Wales Swansea \\ Singleton Park \\ Swansea \\ United Kingdom
}

\begin{abstract}
This paper describes an investigation into the diffusion of information systems development methods (ISDMs). We portray method diffusion as an instance of technological diffusion. Technological diffusion is normally portrayed within the IS industry as an overtly rational process. In this paper, we postulate that the external diffusion process of ISDMs has many features in common with broader social movements and test a model of knowledge-based diffusion. We use the case of the recent history of the dynamic systems development method (DSDM), a public domain standard methodology for rapid application development (RAD), to illustrate some of the key features of method diffusion processes within a UK context.
\end{abstract}

\section{INTRODUCTION}

In this paper, we discuss the topic of the diffusion of information systems development methods (ISDMs) and portray ISDM diffusion as an instance of technological diffusion. Technological diffusion is normally portrayed within the IS industry as an overtly rational process; however, in this paper we postulate that the external diffusion process for ISDMs has many features in common with broader social movements. We utilize the case of the recent history of the dynamic systems development method (DSDM) - a public domain standard method for rapid application development (RAD) - to illustrate some of the key features of method diffusion processes within a UK context. 
The structure of this paper is as follows. First, we define the features of an ISDM and discuss to what degree the study of the diffusion of this "soft" technology reflects "best practice" in the IS industry. Second, we consider the issue of technological diffusion and, by utilizing a knowledge-focused model of technological diffusion to help better understand the phenomenon, make the case for considering methodological diffusion as a social movement. Third, we discuss the case of the ISDM DSDM, which we have used in a preliminary manner to test the efficacy of the model. Finally, we present our conclusions visà-vis the validity of the model, and also call for some much-needed further work in this area.

\section{INFORMATION SYSTEMS DEVELOPMENT METHODS}

While acknowledging the difficulties involved in defining an ISDM (Wynekoop and Russo 1995), for the purposes of this paper we make use of the view that an ISDM comprises the following components (Beynon-Davies 1998):

1. A model of the information systems development process.

2. A set of development techniques.

3. A documentation method associated with these techniques.

4. Some indication of how the techniques chosen along with the documentation method fit into the model of the development process.

5. Some philosophy, which might be defined as the set of assumptions about what constitutes information, an information system, and the place of information systems within organizations.

A systematic survey of the existing literature on ISDMs conducted by Wynekoop and Russo (1997) revealed that over half of the 123 research papers examined consisted of normative research in which concept development was not based on any empirical grounding or theoretical analysis, but merely upon the authors' speculations and opinions. Of those which did constitute empirical research, almost half were undertaken to evaluate ISDMs or parts of ISDMs. Few studies were conducted in order to identify how ISDMs are selected or adapted, or how they are used. There also appears to be little interpretive research and few practice descriptions or case studies.

The lack of an established body of research in this area may be partly due to the fact that there are a number of contradictions inherent in the idea of an ISDM. On the one hand, an ISDM may be viewed as an encapsulation of best practice, while on the other hand it may be viewed as being an organizational fetish. 
The limited evidence on the adoption of ISDMs into industrial practice that we do possess appears to suggest that ISDMs are perceived by practitioners as explicitly representing best practice in the IS industry (Stolterman 1991). As such, we might argue that ISDMs represent an embodiment of social structure, and that changes to an ISDM reflect economic, political, social, and technological changes in the environment of IS work. The structured systems analysis and design method (SSADM), for instance, was created in the early 1980s and has been particularly influential in both public and commercial sectors within the UK. Consequently, a historical study of the diffusion of an ISDM such as this is a cogent way of studying many of the changes that have taken place within the IS industry over the same period.

On the other hand, there is a reasonable body of evidence to suggest that the practitioner community rarely utilize ISDMs in the way they were originally intended. The studies of Edwards et al. (1989) and Fitzgerald (1996), among others, clearly indicate that development organizations either do not use any ISDM in practice, or adapt and use existing ISDMs for their own purposes. Where they are used in their original form, Wastell (1996) has argued that methodologies frequently become used as a fetish and a way of reducing the uncertainty in the development process.

This of course begs the question of why ISDMs are still being created in the IS industry, and why organizations still invest considerable resources in purchasing and attempting to utilize these methodologies. What is perhaps interesting in this light is the finding by Button and Sharrock (1993) that developers frequently rationalize their behavior in deviating from best practice due to project exigencies of limited time, resources, etc.

We argue that there is a middle ground between these two conceptions of ISDMs. The creation and dissemination of ISDMs can be seen as the conventional way in which innovations in development practice are framed within the IS practitioner community. Fitzgerald (1997) argues that there is evidence that ISDMs are useful as a guide for inexperienced developers. Experienced developers frequently diverge from the constructs of a particular method while, at the same time, acknowledging the importance of methodical development. This tends to frame ISDMs in Suchman's (1987) terms as being plans or guides to action, rather than deterministic rules to be followed rigorously.

\section{TECHNOLOGICAL DIFFUSION}

Iacono and Kling (1996) characterize the history of computing in terms of computerization movements and employ this idea to critique conventional notions of the genesis and utilization of computer-based technologies. They argue that conventional answers to the question of why societies computerize fall either into the camp of arguing that computer-based technologies are adopted because they are efficient substitutes for labor or older technologies, or 
that the adoption of computer-based technologies is a reflection of the change from an industrial to an information society. These answers rest on the interaction between two kinds of social actors: vendors of computer hardware and software, and consumers who purchase computer systems and services to meet a perceived need.

This rational account of the genesis and utilization of computer-based technologies has much in common with models proposed in the general literature on the diffusion of innovations. Diffusion is a term originally used in chemistry and biology to describe the processes by which gases move from areas of high concentration into areas of low concentration. Rogers (1998) defines the diffusion of innovations as being "the process by which an innovation is communicated through certain channels over time among the members of a social system." Diffusion studies in this vein seek to trace and explain the path an innovation's acceptance follows through a particular social system over time. Generally, such studies tend to describe diffusion in terms of an S-curve in which a few agents adopt an innovation early on, passing on their experience and influence to the later majority. Factors such as social structures and organizational cultures may facilitate or impede the process.

Iacono and Kling criticize the overtly rational account of technological diffusion for ignoring the contribution of other actors-including colleagues, trade associations in the computer industry, professional societies, regulatory agencies, and the media - in the process of the promotion of computerization. This exhibits similarities with the account of technological diffusion found in the literature (see, for instance, the work of Bijker et al. 1987) on the social construction of technology (SCOT). SCOT accounts of technological diffusion emphasize the way in which complex networks of actors (both human and nonhuman) "configure" particular technologies. For instance, Pinch and Bijker (1987) discuss how, historically, the development process of the bicycle was characterized by conflicting requirements such as speed and safety, conflicting solutions to the same requirements, and various problems such as those of a "moral" nature (women wearing skirts or trousers on high-wheeled bicycles).

This critique leads Iacono and Kling to offer an alternative account of the rise of computer-based technologies. They argue that the rise of computing technologies is

due to a collective action similar to that of other social movements, such as the environmental movement, the anti-tobacco movement, the movement against drinking and driving, or the women's movement...advocates of computerization focus on the creation of a new revolutionary world order where people and organizations use state-of-the-art computing equipment and the physical limitations of time and space are overcome. 
Iacono and Kling proceed to focus upon two key processes critical to computerization: the ways in which movements persist over time through computerization movement organizations (CMOs), and the ways in which CMOs recruit participants.

In order for any social movement to persist over time, pioneering activists must create more enduring organizational structures than those embodied in emergent and informal groups. These organizations are entities capable of taking social action. They can raise money, mobilize resources, hold meetings and formulate positions...computerization movements persist over time with the help of computerization movement organizations. These are organizations, or groups of organizations... which act as advocacy groups for the computerization movement. They generate resources, structure membership expectations, educate the public, and ensure the presence of recognized leaders who can lend their prestige and interorganizational connections to the movement.

They also argue for the importance of members of CMOs and the social network it encourages. "The primary resources of all social movements are members, leaders and some form of social network. Shared beliefs are communicated along these networks and lines of action are advocated." In this sense, CMOs take on the role of framing technologies (Orlikowski and Gash 1994) for their membership by amplifying current problems, interpreting events, and emphasizing the benefits of the transformed social order. A key rhetorical form common to many CMOs is the idea of technological utopianism - the renewal of society through technology.

In this paper, we focus upon two CMOs in order to illustrate our thesis: computer-based education and computer networking. In both these cases, we refer to the apparent lack of any distinct counter-computerization movements. Iacono and Kling tend to focus upon hard technologies such as IT networking to illustrate the social nature of computerization movements. We argue that this perspective also has much to contribute as a framework for the analysis of the diffusion of soft technologies such as ISDMs among the IS community itself.

\section{METHOD DIFFUSION AS A SOCIAL MOVEMENT}

Veryard (1987) equates an ISDM to an IS, and the implementation of an ISDM as both a technological as well as an organizational innovation. He argues that, "the implementation of a new methodology is much more difficult and more critical to the success of the methodology within an organization than the 
selection." We wish to portray the adoption of an ISDM as a diffusion process, as a process in which development approaches are promoted, taken up, adapted, and used among development organizations.

In a rational model of this diffusion process, IS development organizations are the consumers of this technology and vendors of ISDMs are the producers of this technology. The selection of ISDMs by organizations is assumed to be grounded in a rational selection process based upon organizational need. The adoption of a given ISDM is assumed to be related to notions of organizational utility.

Kautz and McMaster (1994) elaborate on a range of factors that enable the diffusion of ISDMs. These factors include prior experience of ISDM introduction, management support and commitment, a clear mission, organizational culture, method usability, education and training, monitoring and evaluation, and good change management. While acknowledging the importance of all of these factors, we wish to emphasize here the importance of the role of CMOs in this diffusion process, and also the way in which members of such CMOs champion particular ISDMs within their organizations.

We may distinguish between internal diffusion of methodologies within organizations, and external diffusion of methodologies between organizations. The former has been studied to a limited extent in relation to the way in which methodologies become adapted and used (Button and Sharrock 1993; Edwards et al. 1989; Wynekoop and Russo 1997). The latter is a topic area which appears to have attracted a much lower level of research activity and has a correspondingly lesser body of knowledge available.

We have found a model recently provided by Newell et al. (2000) to be extremely useful in helping us understand both the internal and external diffusion processes of $\mathrm{RAD}$ among organizations. Newell et al. focus upon the diffusion of knowledge between and within organizations in relation to technology. Figure 1 illustrates the major elements of this model, but adds to it the important position of the CMO.

Diffusion of knowledge involves a process of complex ideas relating to organizations and technical processes that exist in the public domain being bundled together and packaged in particular ways by technology suppliers. These knowledge bundles are designed to create solutions that can be presented by technology suppliers as relatively simple best-practice fixes for organizational problems in a wide variety of contexts. Such knowledge becomes decontextualized or commodified in black boxes that hide its complexity.

Black-boxed solutions are communicated directly to potential users via communication channels linking technology suppliers and users, a process of supply push. However, users do not wait passively for new ideas to be broadcast from the supply side, but actively search out new ideas through boundaryspanning activity. This involves connections with other firms, government bodies, and educational institutions and is described as being process of user pull. 


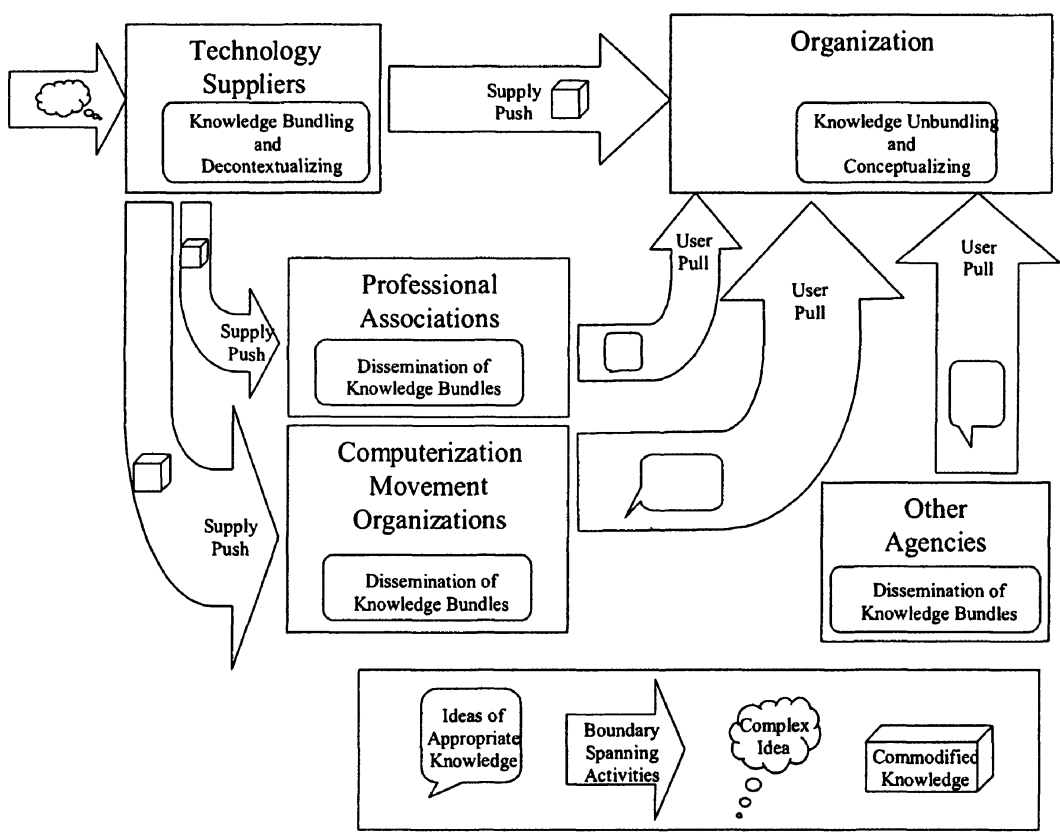

Figure 1. Knowledge-Focused Model of Diffusion (based on Newell et al. 2000)

Newell et al. lay particular emphasis on the importance of professional associations as a network that boundary spanners use in the search process. Knowledge acquired through professional associations is seen to be in some way more neutral than that supplied directly by technology suppliers. However, technology suppliers also use the professional association network to push the same packaged solutions.

Knowledge arrives on the organizational agenda in a black box, by supplier push and/or user pull. However, when knowledge arrives in the organization, it has to be unbundled and contextualized. This process may prove problematic for a number of reasons. For example, the organization may lack an established knowledge-base of people and skills for understanding and applying the technology. Alternatively, the organization may have people with the requisite knowledge and skills but preclude them from the implementation process because of difficulties of internal networking. Frequently it is at this point that consultants are called in to manage the implementation process.

CMOs as we have portrayed them occupy an interesting position between that of technology supplier and professional association. It is for this reason that we have expanded Newell et al.'s model highlighting the position of CMOs as adjuncts to professional associations and acting in concert with such agencies to promote new technologies. 


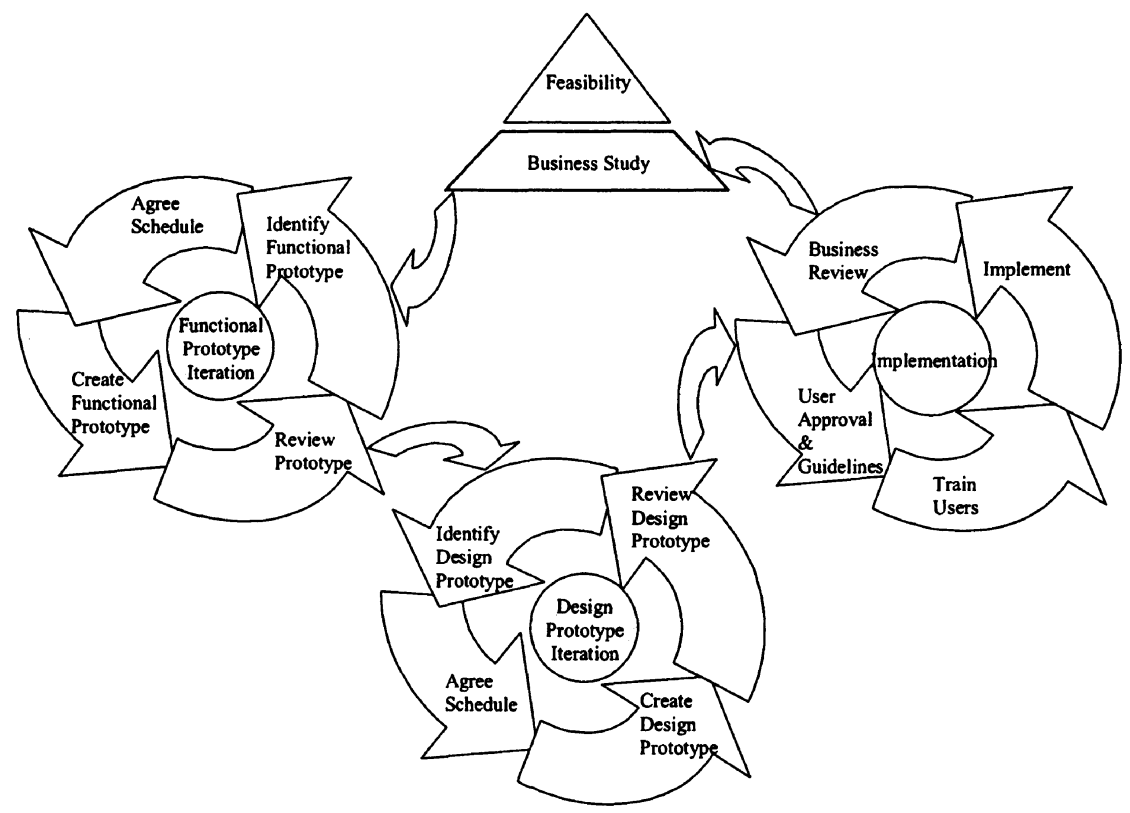

Figure 2. Dynamic System Development Method

\section{THE DIFFUSION OF DSDM}

DSDM was created in 1994 by a number of representatives from a group of UK companies. The DSDM consortium produced a first version of its manual in 1995, a second version of the manual in 1996, and a third and less radical revision of the manual was published in 1997. The 1997 version of the manual has been extended with a number of so-called "white papers" over the last three years.

DSDM can be characterized as an ISDM in that it provides elements in each of the five areas used to define an ISDM:

1. Model of the development process. DSDM utilizes an iterative or incremental model of the development process. This model defines four key phases with iteration both within and between phases as illustrated in Figure 2.

2. Set of techniques. DSDM prescribes the use of a number of new development techniques such as joint requirements planning workshops, joint application design workshops, and time boxing, but generally adopts traditional systems analysis techniques such as entity relationship diagrams in a contingent way. 
3. Documentation method. The method suggests a loose set of documentation approaches. The method generally expects that documentation is kept to a minimum within IS projects.

4. Fit between documentation method and techniques. Some indication is provided in the DSDM manual as to how various techniques and documentation standards may be contingently used in relation to a project.

5. Philosophy. DSDM utilizes a standard philosophy founded in rational business-oriented performance. Unusually for an ISDM, there is also some acknowledgment of cultural issues and of organizational learning within its description of the method.

DSDM can be conceived of as a computerization movement organization (CMO) since it has enabled RAD as a technology to persist over time. Note that we use the term technology here in the broadest sense of the term (familiar in SCOT analyses). In particular, DSDM have:

1. Bundled and decontextualized RAD knowledge.

2. Organized a supply push for RAD.

3. Developed institutional links.

4. Supported boundary spanning activities.

\subsection{Bundling and Decontextualizing of RAD Knowledge}

RAD can be seen to be a set of old and new ideas from the ISDM area. DSDM can be seen to be an attempt to package or bundle RAD, making it easier for consultants to market $\mathrm{RAD}$, and for persons to become accredited suppliers of RAD. One might argue that most ISDMs are attempts to commodify system development knowledge in this way.

RAD in general, and DSDM in particular, may be viewed as being a response to increasing levels of uncertainty both in the business and development domain (Benyon-Davies et al. 1996). DSDM has also served as a focus for amplifying current problems with the software development process such as the contrast between business and engineering quality associated with information technology systems. They have also interpreted current events in the ISD arena and have offered a vision of the benefits of a more iterative approach to systems development such as more ownership and greater commitment from end-users as well as the production of more effective business systems.

\subsection{Organizing a Supply Push for RAD}

DSDM has carried out a number of activities that have provided a supply push for RAD as a soft technology. It has: 
1. Raised funds through organizational membership both of an individual and corporate kind. Many organizations within the UK have subscribed to the DSDM approach. Currently, the consortium lists over 240 full members including British Telecom, Computer Associates, Oracle, Price Waterhouse, Coopers and Lybrand, KPMG, and the Post Office. DSDM also has branches in the Netherlands, Sweden, Denmark, India, and in the U.S. Participating organizations have adopted and adapted the DSDM framework, utilized DSDM as their RAD route in corporate methodologies, and trained personnel in DSDM.

2. Mobilized resources. DSDM now administers an accreditation program (linked to British Computer Society professional accreditation). A key part of this accreditation involves vetting training courses run by commercial vendors. There is also a route for consultants to become accredited in the use of DSDM.

3. Held meetings throughout the UK to proselytize the benefits of the approach. Members of the consortium have promoted the method in venues such as British Computer Society specialist group meetings and other industrial seminars. DSDM members have also been particularly active in "evangelizing" the benefits of this $\mathrm{RAD}$ approach at one-day awareness events throughout the UK. An annual DSDM conference has become an established event, having run for a number of years.

4. Formulated positions. The DSDM consortium produces a regular newsletter for its members. The consortium also regularly produces white papers on key extensions to the method. More recently a key member of the consortium, Jennifer Stapleton, produced a book documenting the ISDM (Stapleton 1997). This literature is employed particularly to formulate positions in opposition to traditional development approaches such as those philosophically aligned to the waterfall model. The literature also promotes the opposition of true or second generation $\mathrm{RAD}$ to hacking or first generation RAD. DSDM portrays itself as a disciplined development approach interested in the business quality of systems.

\subsection{Development of Institutional Links}

DSDM has been adopted by a number of IS/IT consultancies and proffered as a service. Close links have been developed between DSDM members and members of professional associations, particularly the British Computer Society (BCS), with the BCS eventually lending its weight to accrediting DSDM practitioners. Links have also been forged with other agencies; for instance, a number of UK universities joined DSDM and have started to offer DSDM accreditation to their students. 


\subsection{Boundary Spanning Activities}

DSDM has been extremely successful in enlisting and supporting champions of the method within particular organizations. In one organization to which we had access, a number of business analysts were originally promoting an in-house development approach with RAD features. Members of this consultant group were early participants in setting up the DSDM consortium and consequently the organization became one of the first large-scale adopters of the development approach. RAD consultants within this organization now run both one-day RAD awareness courses and three-day $\mathrm{RAD}$ practitioner courses for both members of the organization and others. Another organization became a DSDM member in 1996, following a developing interest from a small group of practitioners within the organization. Explicitly, RAD and DSDM were promoted by the new technology group within the organization and an internal methods expert (a DSDM member). A RAD/DSDM route has now been written into the formal corporate ISDM.

Boundary spanning activities and user pull were certainly evident in the two organizations studied. The first organization already had a base of experience of RAD prior to the creation of the DSDM consortium. Organizational members skilled in this technology were quick to jump on the DSDM bandwagon, although interestingly their adoption of DSDM as a corporate standard does not seem to have changed their in-house RAD approach to any significant degree. In the second organization, the new technology group was looking for new development approaches to help with solving a severe image problem at the development center. Two members of the new technology group attended commercial seminars on RAD and DSDM as well as those run by professional associations such as the BCS.

Because of their prior base of knowledge, skills, and personnel, the first organization was far more able to decontextualize DSDM as a technology for the organization. The major effort appears to have been one of translation between the prescriptions of DSDM and that of the existing in-house method. The second organization had no prior experience of RAD approaches. DSDM was selected on the basis of championing by members of the new technology group but experienced a number of difficulties of adaptation into the accepted practices of the organization. Although a DSDM route was written into the corporate ISDM standards, the flagship project experienced a number of problems in adapting DSDM prescriptions to the expectations of both developers and users within the organization.

\section{CONCLUSIONS}

Methodological diffusion has many characteristics in common with social movements. The idea of computerization movements provides a valuable counter 
to the rational model of diffusion characteristic of portrayals of technological diffusion. ISDMs are an important soft technology in that, at least overtly, they are meant to embody best practice in IS development. This idea of best practice supports a rational accounting of method diffusion. The explanation of low takeup of methods and considerable adaptation of methods within organizations is usually accounted for in rational terms such as the cumbersome nature of ISDMs and the difficulties of implementation (Chatzoglou and Macauley 1996).

In this paper, we have provided a social constructivist interpretation of the diffusion of ISDMs. In particular, we have emphasized the importance of computerization movement organizations to the take-up of technologies and considered the way in which organizations such as DSDM can be regarded as CMOs. We have also considered the diffusion of ISDMs in the light of Newell et al.'s (2000) knowledge-based focus on technological diffusion.

The main lessons to be drawn are:

1. Methods are particularly useful as knowledge bundles for diffusion. DSDM can be seen to be an attempt to package or bundle RAD, thus making it easier for its transmission and promotion among organizations, consultants, and professional organizations.

2. CMOs are important to the effective external diffusion of ISDMs. In terms of external diffusion, CMOs are important to ISDM diffusion in providing a coherent discourse and rationale for method innovation. In our case, DSDM has proven to provide a significant focus in organizing the debate about the applicability of RAD to information systems development, at least within the UK context. CMOs, therefore, seem to play, along with professional associations, an important mediating role between suppliers and users of technology. They are critical both to the processes of supplier push and user pull in technological diffusion.

3. ISDM diffusion occurs through processes of user pull, supply push, and boundary spanning. ISDM knowledge bundles are promoted by consultancies in professional associations and supported by other institutions such as universities. Organizations are attracted to the best practice promoted by ISDMs and their CMOs. Individuals within such organizations initiate the diffusion process by promoting the ideology of an ISDM within the organization.

4. Significant external diffusion does not necessarily need to occur prior to internal diffusion. Our case material suggests that some organizations are early adopters of innovative approaches and may significantly contribute to the formation of CMOs within the domain.

5. Internal diffusion is enabled by the recruitment of organizational members to such CMOs. In this process they become internal champions for the ISDM and communicate the shared beliefs of the CMO internally within the organization. Both of the organizations studied maintained large development centers, an in-house monolithic method, and RAD was consequently 
a relatively new innovation in both organizational environments. In one organization, a small group of champions were in the early stages of promoting the ISDM approach. In the other, champions of the ISDM had successfully developed a formal role for themselves in promoting the innovation.

6. Links to external CMOs via internal and external consultants are important vehicles for supporting the diffusion process. The existence of external CMOs lends weight to the need for organizational adoption. However, the success of ISDM adoption is also influenced by the interplay between the activities specified in the method and the structure and culture of an organization. For instance, we have evidence of the difficulties inherent in utilizing RAD within a highly centralized and bureaucratic organization, a conclusion supported by the work of Jones and King (1998). In such an organization, relatively low degrees of user empowerment are commonplace among projects. This makes it difficult to introduce changes to the expected levels of such involvement on projects, a key principle of RAD work.

We acknowledge that while we do not yet have sufficient data to provide substantive evidence to support the propositions we have outlined, the paper does provide preliminary evidence that validates a number of aspects of a knowledge-focused perspective on diffusion. However, it clearly needs verification in a larger-scale case study. We are particularly interested in undertaking such a study among a range of organizations. We are also interested in revisiting some of the organizations to which we gained initial access some years ago with the aim of studying the continuing diffusion of DSDM as a method within these companies.

\section{ACKNOWLEDGMENTS}

The work on this project was funded by the UK Economic and Social Research Council (Grant No. R000 23 5505). We would like to thank all those at participating organizations who agreed to talk to us about, as well as letting us observe, their RAD work. Thanks also to colleagues on this research project: Douglas Tudhope, Hugh Mackay, Roger Slack, and Chris Carne.

\section{REFERENCES}

Beynon-Davies, P. Information Systems Development: An Introduction to Information Systems Engineering, London: Macmillan, 1998.

Beynon-Davies, P., Mackay, H., Tudhope, D. S., and Slack, R. "Rapid Application Development: The Future for Business Systems Development?" in Business Information Technology 
Conference, R. Hackney (ed.), Manchester Metropolitan University, Manchester, England, October 20-21, 1996.

Bijker, W. E., Hughes, T. P., and Pinch, T. (eds.). The Social Construction of Technological Systems: New Directions in the Sociology and History of Technology, Cambridge, MA: MIT Press, 1987.

Button, G., and Sharrock, W. "Practices in the Work of Ordering Software Development," in The Discourse of Negotiation, A. Firth (ed.). Oxford: Pergamon Press, 1963, pp. 159-180.

Chatzoglou, P. D., and Macauley, L. A. "Requirements Capture and IS Methodologies," Information Systems Journal (6), 1996, pp. 209-225.

Edwards, H. M., Thompson, J. B., and Smith, P. "Experiences in the Use of SSADM: Series of Case Studies. Part 1: First-Time Users," Information and Software Technology, 1989, pp. 411-426.

Fitzgerald, B. "Formalized Systems Development Methodologies: A Critical Perspective," Information Systems Journal (6), 1996, pp. 3-23.

Fitzgerald, B. "Systems Development Methodologies: A Need for New Canons," Working Paper, University College, Cork, 1997.

Iacono, S., and Kling, R. "Computerization Movements and Tales of Technological Utopianism," in Computerization and Controversy: Value Conflicts and Social Choices, R. Kling (ed.), Englewood Cliffs, NJ: Prentice-Hall, 1996, pp. 34-56.

Jones, T., and King, S. F. "Flexible Systems for Changing Organizations: Implementing RAD," European Journal of Information Systems (7), 1998, pp. 61-73.

Kautz, K., and McMaster, T. "The Failure to Introduce System Development Methods: A FactorBased Analysis," in Diffusion, Transfer and Implementation of Information Technology, L. Levine (ed.), Amsterdam: Elsevier/North Holland, 1994.

Newell, S., Swan, J. A., and Galliers, R. D. "A Knowledge-Focused Perspective on the Diffusion and Adaptation of Complex Information Technologies: The BPS example," Information Systems Journal (10), 2000, pp. 239-259.

Orlikowski, W. T., and Gash, T. C. "Technological Frames: Making Sense of Information Technology in Organizations," ACM Transactions on Information Systems (12:2), 1994, pp. 17-207.

Pinch, T. J., and Bijker, W. B. "The Social Construction of Facts and Artifacts: Or How the Sociology of Science and the Sociology of Technology Might Benefit Each Other," in The Social Construction of Technological Systems, W. J. Bijker, T. P. Hughes, and T. Pinch (eds.), Cambridge, MA: MIT Press, 1987.

Rogers, E. M. Diffusion of Innovations (3 ${ }^{\text {rd }}$ Edition), New York: Free Press, 1998.

Stapleton, J. DSDM-Dynamic Systems Development Method: The Method in Practice, Harlow, England: Addison-Wesley, 1997.

Stolterman, E. "How System Designers Think About Design and Methods: Some Reflections Based on an Interview Study," Journal of Information Technology (3:1), 1991, pp. 137-150.

Suchman, L. A. Plans and Situated Actions: The Problem of Human-Machine Communication, Cambridge, England: Cambridge University Press, 1987.

Veryard, R. "Implementing a Methodology," Information and Software Technology (29:9), 1987, pp. 469-474.

Wastell, D. "The Fetish of Technique: Methodology as a Social Defense," Information Systems Journal (6), 1996, pp. 25-40.

Wynekoop, J. L., and Russo, N. L. "Studying System Development Methodologies: An Examination of Research Methods," Information Systems Journal (7:1), 1997, pp. 47-65.

Wynekoop, J. L., and Russo, N. L. "Systems Development Methodologies: Unanswered Questions," Journal of Information Technology (10), 1995, pp. 65-73. 


\begin{abstract}
About the Authors
Paul Beynon-Davies spent several years in the information systems industry before taking up an academic post. He is currently a reader in Information Systems in the European Business Management School, University of Wales, Swansea. He has written a number of books on information systems topics and regularly publishes journal papers, conference papers, and professional articles on issues concerning information systems development. Dr. Beynon-Davies has conducted research in the areas of database systems, hypermedia, information systems development and information management. He has acted as a regular consultant to industry for a number of years. He can be reached by e-mail at p.beynon-davies@swan.ac.uk

Michael D. Williams holds a B.Sc. from the University of Glamorgan, and a Ph.D. from the University of Sheffield. Prior to entering academia, Dr. Williams spent 12 years developing and implementing information systems in a variety of domains in both public and private sectors for organizations including British Telecom, Chartered Trust PLC, and Canon UK LTD. Since entering academia, he has held full-time academic posts at institutions including the University of Glamorgan and the University of Sheffield. He is currently a member of the academic staff at the University of Wales Swansea. Dr. Williams is the author of numerous fully refereed and invited papers covering a variety of areas within the information systems domain. His current research interests are focused primarily upon the areas of information systems evaluation, information systems development, and the use of information and systems. He can be reached by e-mail at m.d.williams@Swansea.ac.uk.
\end{abstract}

